\title{
The Fish Model: When Do Researchers Collaborate Online?
}

\author{
Bahaaeldin Mohamed and Thomas Köhler
}

\begin{abstract}
The questions of whether and how doctoral students are motivated for enhanced research collaboration deserve thorough consideration. Even though collaboration in general and its mediated forms, such as computer-supported cooperative work and collaborative learning (CSCW and CSCL), are prominent research topics, only a little is known about the methods necessary to design various activities to support research collaboration. With the upcoming generation of tools such as Mendeley, Conference Chair, ResearchGate, or Communote, scholars suspect that web 2.0 services play a decisive role in enabling and enhancing research collaboration. However, there is almost no data available on the extent to which researchers adopt these technologies, and how they do so. Therefore, the authors first present an overview of the current usage of web 2.0 among doctoral researchers in their daily academic routines, based on a survey $(n=140)$ conducted in the German Federal State of Saxony. It confirms a wide and often specified usage of web 2.0 services for research collaboration. For theoretical analysis, the authors propose a conceptual framework that reflects the requirements of scientific participation and scholarly collaboration within an average international doctoral programme adopting current digital technologies. The aim of this framework is to understand, support, and enhance research collaboration among doctoral researchers. Our fish model highlights the mutual relationship between the following dichotomous factors: (a) tasks/time factors; (b) beliefs/activities; (c) support/context; and (d) incentives/ethical issues. Our results indicate a significant relationship in terms of research collaboration. This relationship has particularly been identified between two dichotomous factors: beliefs/activities and incentives/ethics.
\end{abstract}

Keywords Research collaboration · e-science $\cdot$ Web 2.0 technology $\cdot$ Scholarly communication $\cdot$ Doctoral training

\author{
B. Mohamed ( $\square)$ \\ British Lincoln College, Riyadh, Saudi Arabia \\ e-mail: bahaa@bzoor.com \\ T. Köhler \\ Institute for Vocational Education, TU Dresden, Dresden, Germany \\ e-mail: thomas.koehler@tu-dresden.de
}




\section{Introduction}

Research collaboration is the foundation of research students' efforts in academia. Independently of disciplinary background, research is based on the social patterns of competition for the best explanation and joint evaluation of the quality of research. Therefore, research collaboration is a form of positive interaction between knowledge producers that have taken on management roles by using certain resources and tools to establish and pursue a scientific goal (Ynalvez et al. 2011). We define research collaboration as the current and future regulations, processes, and concepts which support interaction and cooperation between our doctoral candidates. Here, it is important to note that collaboration is not simply students and professors coauthoring a piece of research; instead, it requires establishing connections that might extend to communication which, over time, develops into sustainable collaboration among different researchers with similar interests. Accordingly, we may need to better understand the nature of scientific tasks and the time frame in which they should be completed, as well as how individual beliefs of using ICT and web 2.0 in a research context can help to define how online activities should be organised. In addition, the use of technology can be interpreted in relation to cultural contexts and disciplines. Finally, incentives act as the engine that encourages students to undertake collaborative research, and, in academia, this engine is covered and protected by research ethics. In this paper, we focus on collaboration of all $\mathrm{PhD}$ students in their first, second, or third year. This may take into consideration the form of any formal or informal social action and scientific activities that could increase the output and production of scholarly research, improve communication through the text, and encourage resource sharing and collaborative writing.

$\mathrm{PhD}$ students face new challenges in the age of digital research. In particular, this paper focuses on challenges such as dealing with digital material and resources, learning management systems, personal learning environments, social networks, and collaboration in research networks. Current $\mathrm{PhD}$ students, who are largely from the Generation Y demographic group (born between 1982 and 2000), are familiar with technology and are likely to encounter one or more web 2.0 technologies in their everyday life (Zaman 2010). In the academic context, web 2.0 technology shapes how $\mathrm{PhD}$ students learn, self-regulate, and communicate. Accordingly, universities have begun to use and provide these facilities of infrastructure to attract and connect students and develop-step by step-a better practice for research collaboration. However, as Zaman (2010) reports, current doctoral programmes struggle to follow up and meet these demands and requirements. Concerning social and scientific interaction and collaboration among our doctoral students, Mohamed et al. (2013) investigated $\mathrm{PhD}$ students' attitudes towards doctoral colloquium, online learning material 
via Edu-tech, ${ }^{1}$ and learning management systems via OPAL. ${ }^{2}$ These scientific activities were used simply to provide an informative website for learning material and scientific events; PhD candidates usually found that the community of practice and the feeling of belonging were lacking.

We expect the digital form of research so-called e-research collaboration to comprise the attempt to enhance and develop not only scientific activities such as co-authorship or finding peers and peer reviewers, but what we refer to as "openkitchen research". This term refers to sharing research activities not only as a finished product, but also as processes. In fact, during the doctoral candidate education, they attempt to communicate and collaborate only in the context of theoretical curriculum. These learning formal courses are traditionally designed to provide students with only structured theoretical knowledge but no real practices. In most cases, we observed that part-time $\mathrm{PhD}$ students working in third-party projects at our laboratory give priority than ever before to the projects they are working in where there is more community support than working individually with their own dissertation.

The relevance of this study can be confirmed by the fact that doctoral education in Germany is rapidly growing in all academic disciplines, to a recent total number of 200,400 doctoral candidates being supervised at German universities (in the winter semester 2010/2011), while only half of this group $(n=104,000)$ was officially registered (Forschung \& Lehre 2012; Wolters and Schmiedel 2010). How do those registered scholars participate in research activities? Do they follow their academic activities at the same pattern and do they regularly use the same research online tools? We can just guess that the new openness of social media and web 2.0 communication helps to provide similar conditions and borderless collaboration for all scholars depending on their access to the Internet. In the German Federal State of Saxony, where the data of this study was collected, the number of $\mathrm{PhD}$ degrees has increased more than tenfold, from $n=111$ in 1993 to $n=1,206$ in 2009 (Saxony State, Statistical Branch 2009).

In order to provide an adequate statement about how our novice researchers collaborate via using web 2.0 services, we explore which factors might shape this collaboration, particularly the collaborative opportunities offered by web 2.0 , we begin by developing a theoretical framework for our investigation, and apply it to the current situation of PhD students in Germany.

\footnotetext{
${ }^{1}$ This study focused on the European doctoral network "Education \& Technology" (cp. http://edutech.eu).

2 OPAL, an open-source Learning Management System, used by all universities of the Federal German State of Saxony (cp. https://bildungsportal.sachsen.de/).
} 


\section{The Fish Model: A Conceptual Framework for E-Research Collaboration}

The authors conceptualised e-research collaboration as follows. Based on a metaanalysis, approximately 200 papers focussing on different aspects and approaches in e-science and e-humanities were recruited, organised, and analysed, in order to formulate a proposed conceptual framework, the fish model, previously published in Mohamed et al. (2013). The framework may be used to deepen our understanding of the daily scientific tasks, activities, technologies, and incentives that shape everyday academic practices for doctoral scholars, regardless of their disciplinary heritage. Databases consulted include Science Direct, Pro-quest, EBSCO, Scirus, and Mendeley. Inclusion criteria were limited to full-text papers concerning the use of web 2.0 in research communication and collaboration. Keywords used for collecting scientific articles directly from the mentioned databases included the following: researchers' digital habits, use of web 2.0 in research, e-research, social media in research, research collaboration, and scholarly communication. The following selection criteria were used for papers: (1) written in English, (2) situated only on the $\mathrm{PhD}$ and researcher levels, (3) either empirical or review articles only. In addition, a conceptual definition of collaboration factors from Patel et al. (2011) and the Folk Model of Intentionality (DeAndrea 2012) were used as guides to identify the fish model (Ringle et al. 2005). The first step in analysing the selected papers was to interpret online research behaviours and the academic activities associated with using web 2.0 technologies, in order to predict the future of research collaboration, using the Fish Model (Mohamed et al. 2013). As the model clarifies the factors and concepts behind the best practices associated with research collaboration using web 2.0 technologies, it was proposed to develop an understanding of daily scientific research tasks and activities.

As the authors suggested earlier, online research behaviour is controlled by some key factors and indicators, which was first framed in the Model of Collaborative e-Research (Reebs 2011). This model can be used to describe the factors that support online collaboration in e-science. The fish model (Mohamed et al. 2013), however, extends this research by giving evidence that individual factors (beliefs, self-regulation, etc.), in addition to group interaction organised by the institution, and time management, obviously influence the active production of research, communication among researchers, and subsequent collaboration. Using the fish model, the core factors in online research behaviours and the academic activities associated with using web 2.0 technologies all were investigated.

It is argued that a doctoral scholar would behave "like a fish living in a specific environment, taking part in a particular community, showing different individual behaviours to respond to an action, led by their own beliefs and framed by a certain culture" (Mohamed et al. 2013, p. 3275). Typical behaviours and activities are managed by incentives related to the qualification addressed and controlled by the scholar's role in the research ecology. The fish metaphor emerged when framing a body of collaboration patterns for the authors' previous study (Frewox 2010). 
"Collaboration in research is managed by a dorsal fin to stabilise research against rolling and protect scientific environment from isolation and weakness. Inhalation through the mouth passes over the gills in fish to obtain fresh oxygen, communication is the oxygen of research project which is necessary for bringing activities and ideas to the project and achieve the tasks related. The backbone of our fish is web 2.0 technologies which connect and facilitate all functions of the whole body, these functions are divided concerning a dichotomous aspect (fish spine) - as we will describe it complementarily in the frame of this paper - in a task/time, activities/beliefs, support/context, and ethics/incentives division" (Tannen 2006, p. 3267 ff.).

Research collaboration is usually considered as a planned activity where knowledge can be produced and transferred. The authors predicted previously (Mohamed et al. 2013) that collaborative e-research (using web 2.0 technology to improve best research practices) will take place alongside dichotomies. Tannen (Wang 2010), in his book, The Argument Culture (1998), proposes the concept of perceived dichotomies, that is, binarisms between two connected concepts, while not distinguishing between them through the use of vocabulary such as "good" and "bad". Building on Tannen's work, the fish model proposes the integration of both factors. Research collaboration in this study can be interpreted as a relationship between eight concepts formed in pars making up the total of four groups: (a) between scientific tasks or candidates' needs and time available for implementing them; (b) between planned activities and individual research beliefs in dealing with these activities; (c) support from technology and understanding the uses of this technology within a certain context and culture of an institution; and (d) intentions/motivations for collaboration, which are directed by research ethics, as illustrated in Fig. 1.

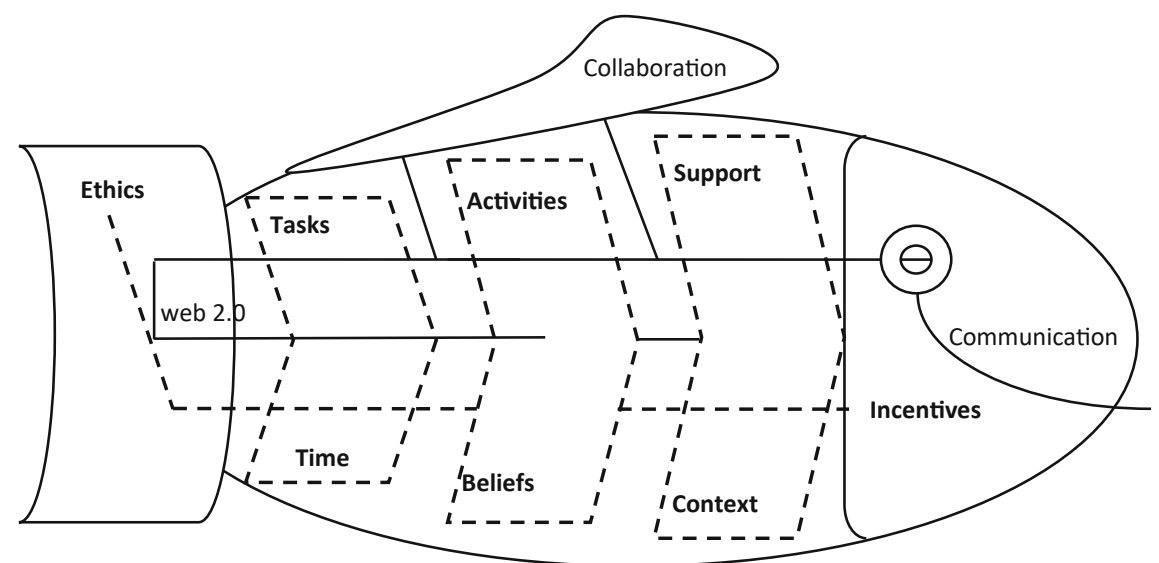

Fig. 1 Fish model: conceptual framework for developing e-research collaboration for $\mathrm{PhD}$ students and novice researchers (Mohamed et al. 2013) 


\subsection{The Reality of Managing Scientific Tasks in Terms of the Available Time}

It can be expected that novice researchers are likely to collaborate and work with each other because they are more likely than experienced researchers to break their work down into various tasks, activities, and actions. Such individual behaviour is controlled by time management as short-/long-term academic tasks, primarily related to different actions such as information search, data analysis, reading, or possibly writing (Illeris 2004). Overall, the doctoral education system differs significantly from programmes at masters and bachelor level, as doctoral programmes prepare candidates for high-level careers in industry or provide long practical experience (Zaman 2010). In their previous studies (Mohamed et al. 2013; Mohamed et al. 2013), the authors identified two key tasks that doctoral students undertake in order to carry out their research. The first is marketing, that is, building a scientific competence profile in order to develop a scientific reputation. The second is doing research, that is activities in daily research practice, including mainly reading, writing, investigating, searching, and reviewing.

H1: Novice researchers are more likely to collaborate and work with each other when the work task (types, stages, and technologies) and timeframe are specified.

H1-0: An academic task to be done via web 2.0 is driven by a timeframe (when the task should be done/how much time is needed to do it).

H1-1: An appropriate timeframe for a task to be carried out via web 2.0 can lead to academic collaboration

\subsection{Online Research Activities Led by Work-Based Beliefs}

$\mathrm{PhD}$ students' daily research activities include specific online activities, as identified previously (Mohamed et al. 2013): accessing resources, information, and research funds; engagement in scientific discussions and being an active member in one or more academic communities of practice; communication in reviewing, sharing, and exchanging ideas; awareness of recently published scientific papers and events; presenting oneself online in social media and social networking in order to build up a profile and identification (Mohamed 2011; Lahenius 2010; Peggy and Borkowski 2007).

Typically, it is expected that $\mathrm{PhD}$ research work is completed through three main development phases (Terrell et al. 2009; Zaman 2010; Mohamed et al. 2013): (a) becoming a researcher by training, and reading activities for first-year PhD students; (b) becoming an expert in any required methods and the pressure to start publishing for second-year PhD students; and (c) becoming an author which includes participating in peer reviewing, co-authoring, and writing publications. Each of those phases requires a number of planned online activities. Additionally, gradual engagement 
with the literature of one's own scientific discipline should be considered, because it leads to particular work beliefs. Three main explanations for scholars' success were identified (Patel et al. 2011): social culture, the culture of disciplines, and the individual beliefs (values, motivation, learning style, self-regulation, cognitive competence, confidence, and trust). Usually, beliefs are addressed by psycho-educational research, whereas the role of trust (versus control) as a governance concept has been addressed in earlier research on virtual organisations (Lattemann and Köhler 2005). Only the combination of these accepted beliefs defines a researcher's individual approach to scientific activities.

H2: Novice researchers are more likely to collaborate and work with each other when they believe in the work and participate in academic and research activities (online).

H2-0: Academic activities (online) affect a researcher's belief in using web 2.0 toward collaboration.

H2-1: Researchers' belief in using web 2.0 for research may increase their chances of collaboration

\subsection{Support for Technology Use in Context}

Even though web 2.0 is a rather young technology, multiple studies have investigated its benefits for learning, especially in the production and communication of scientific research, or e-science (Pscheida et al. 2013; Kahnwald et al. 2015). A core aspect of ICT infrastructure (web 2.0) is its strong linkage to the sociocultural context and the disciplinary culture. While academic work triggers social interactions among $\mathrm{PhD}$ scholars, the cultural context drives and assists their use of web 2.0 technologies in order to interact. ICT and web 2.0 services in learning and research comprise all methods, techniques, online behaviours of scientists, tools used by researchers, knowledge sharing and transfer, acceptance/adoption, and building social networks via e-research identified by literature reviews (Meyer and McNeal 2011). A doctoral candidate's use of web 2.0 technologies is both supported by and understood through institutional context and discipline culture (Pscheida et al. 2013). Those have a particular need for being involved in one or more academic communities on a national or international level in order to share and develop practice successfully, usually realised through web 2.0 services (Veletsianos and Kimmons 2012; Eyman et al. 2009; Illeris 2004; Gillet et al. 2009; Lam 2011).

H3: Researchers are more likely to collaborate when they have received technical support in their academic context.

H3-0: web 2.0 technology may enhance research communication, leading to future collaboration.

H3-1: Research context has a direct influence on collaboration 


\subsection{Incentives Protected by Research Ethics}

PhD candidates need incentives to be strongly engaged in online collaboration (Pidd 2011); these incentives are intrinsic motivation, satisfaction, and reputation. Purely financial motivation is less important, but the motivation should be protected and controlled by research ethics related to the digital environment (Mutula 2010). The issue of trust should be considered by faculty involved in digital research processes (Jirotka et al. 2006), as it has a special role in steering online networks (Lattemann and Köhler 2005). Young researchers need to develop e-strategies to use research portals to ensure and facilitate authentic human sources for knowledge transfer. While the majority of them have adopted web 2.0 tools already, their willingness to shift from offline to online digital research practices is crucial (Pscheida et al. 2013; 2014) to build trust and protect scientific work in a virtual environment (Lam 2011).

H4: Novice researchers are more likely to collaborate and work with each other when they receive incentives (as external motivation) that are protected and combined with their trust and the value of their work (as internal motivation).

H4-0: Incentives as an external motivation can influence ethics as an internal motivation for enhancing research collaboration.

H4-1: Research ethics as an internal motivation is closely related to research collaboration

\section{Method}

For this paper, data was collected and analysed through the combination of two main methods: (a) description of a quantitative online survey conducted in the German Federal State of Saxony from 22 July 2012 until 22 October 2012, at the Technische Universität Dresden and (b) forming and testing the structured model. The main aim was to investigate novice researchers' intentionality to collaborate with each other through the use of web 2.0 and digital online technologies in academia. Our survey included two main parts: the first part reveals demographic data and the second part includes a 5-interval Likert scale with points ranging from 1 (strongly disagree) to 7 (strongly agree). The survey addressed doctoral students as novice researchers who are using web 2.0 technology to communicate and collaborate in research daily life. This 45-item measure was created for this study to assess participants' perceptions, profiling the nine main factors that shape the final structure of the fish model: task, time, activity, belief, support, context, incentive, ethics, and collaboration. The instrument was then tested by three independent experts in research collaboration before being given to respondents from the target audience. The authors received a total return of $n=140$ doctoral students who completed the survey. The data was examined using factor analysis and our fish model was tested with the Partial Least Squares (PLS) technique. SmartPLS, Version 2.0 M3 software was used to test the model (Ringle et al. 2005, p. 1). 


\section{Results}

The majority of respondents $(57.71 \%)$ were male, $66.74 \%$ were not married and had no children, and $30.45 \%$ of respondents were from the School of Science, which includes the $13.41 \%$ which were PhD students from the Faculty of Mechanical Engineering. This can be considered typical for Saxony's higher education landscape, as it has a special focus on technical subjects.

\subsection{The Measurement Model}

PLS is "the second-generation structural equation modelling technique that assesses both the measurement and structural model in a single run" and was chosen for two reasons: it works well for smaller sample sizes and eliminates restrictions on data distribution such as normality (Serenko 2008, p. 465). Before analysing this model, its reliability was measured. Cronbach's alpha exceeded the required threshold of 0.7 for all items, implying high internal consistency of the scales (Serenko 2008).

In order to submit an accepted level of eligibility for the questionnaire, half of the items (24 of 45 items) were removed which do not have sufficient weight vis-à-vis their main factor (Table 5, see Appendix). Once these items were removed, the model was re-estimated. Reliability results are given in Table 1. The data shows that the measures are robust in terms of their internal composite reliability. The composite reliability of the different items ranges from 0.8 to 1.0 , above the recommended starting value of 0.70 (Serenko 2008). In addition, consistent with the guidelines of Fornell and Larcker (Birnholtz 2005), the average variance extracted (AVE) for every component is above 0.50 . Table 2 presents the results of measuring the discriminant validity for variable constructs. The matrix diagonal reports that the square roots of

Table 1 Assessment of the measurement model

\begin{tabular}{l|l|l}
\hline Variable constructs & $\begin{array}{l}\text { Composite reliability (internal } \\
\text { consistency reliability) }\end{array}$ & $\begin{array}{l}\text { Average variance } \\
\text { extracted/explained (AVE) }\end{array}$ \\
\hline Time & 0.80 & 0.57 \\
\hline Task & 0.80 & 0.57 \\
\hline Support/tech & 0.88 & 0.66 \\
\hline Incentives & 0.83 & 0.62 \\
\hline Ethics & 1.00 & 1.00 \\
\hline Context & 0.82 & 0.69 \\
\hline Collaboration & 0.84 & 0.58 \\
\hline Beliefs & 0.83 & 0.62 \\
\hline Activities & 0.85 & 0.59 \\
\hline
\end{tabular}


Table 2 Discriminant validity (inter-correlations) of variable constructs

\begin{tabular}{l|l|l|l|l|l|l|l|l|l}
\hline Latent variables & 1 & 2 & 3 & 4 & 5 & 6 & 7 & 8 & 9 \\
\hline 1. Time & 1.00 & & & & & & & & \\
\hline 2. Task & 0.67 & 1.00 & & & & & & & \\
\hline 3.Support/Tech & -0.43 & -0.39 & 1.00 & & & & & & \\
\hline 4. Incentives & -0.23 & -0.20 & 0.59 & 1.00 & & & & & \\
\hline 5. Ethics & -0.32 & -0.30 & 0.37 & 0.33 & 1.00 & & & & \\
\hline 6. Context & -0.027 & -0.10 & 0.30 & 0.23 & 0.00 & 1.00 & & & \\
\hline 7. Collaboration & -0.31 & -0.30 & 0.50 & 0.50 & 0.46 & 0.06 & 1.00 & & \\
\hline 8. Beliefs & -0.44 & -0.36 & 0.66 & 0.53 & 0.49 & 0.11 & 0.65 & 1.00 & \\
\hline 9. Activities & -0.28 & -0.22 & 0.35 & 0.37 & 0.34 & 0.25 & 0.41 & 0.54 & 1.00 \\
\hline
\end{tabular}

the AVEs are greater in all cases than the off-diagonal element in their corresponding row and column, which supports the discriminant validity of the instrument.

The instrument was tested additionally through PLS-Graph and for convergent validity. Table 4 (see Appendix) shows the factor loading of all items to their respective latent constructs. All items loaded on their respective construct from a lower pound of 0.70 to the upper pound of 0.85 . In addition, the $T$-test of outer model loading in the PLS-Graph output was highly significant $(p<0.001)$ for each factor's loading on its respective construct. The results confirm the convergent validity as demonstrating a distinct latent construct.

\subsection{The Structured Model}

Figure 2 presents the results of the structured model with interaction effect. In order to assess the structured model, a bootstrapping technique was applied. The examination of $t$-values was based on a 1-tail test with statistically significant levels of $p<0.05$ $(*), p<0.01(* *)$, and $p<0.001(* * *)$. Dotted lines highlight the insignificant paths. Structured components were formulated by multiplying the corresponding indicators of the predictor and moderator construct.

For clarity purposes, the outcomes of the structural model in terms of direct effects, bootstrapping, and $t$-statistics confirmed the majority of the hypotheses, at various significance levels. However, the results show that only two factors in research collaboration are associated significantly (Fig. 2). Specifically, "Academic activities" is very significantly associated with "Researchers' beliefs" (H2-0 at $\beta=-0.67, p<$ 0.001 level). In this first path, "Researchers' beliefs" has a significant relation with "Collaboration" (H2-1 at $\beta=0.41, p<0.001$ level). In the second path, "Incentives" and "Ethics" contribute significantly to "Collaboration". Accordingly, (H4-0) confirms a significant relation between "Incentives" and "Ethics" (H4-0 at $\beta=0.71$, 


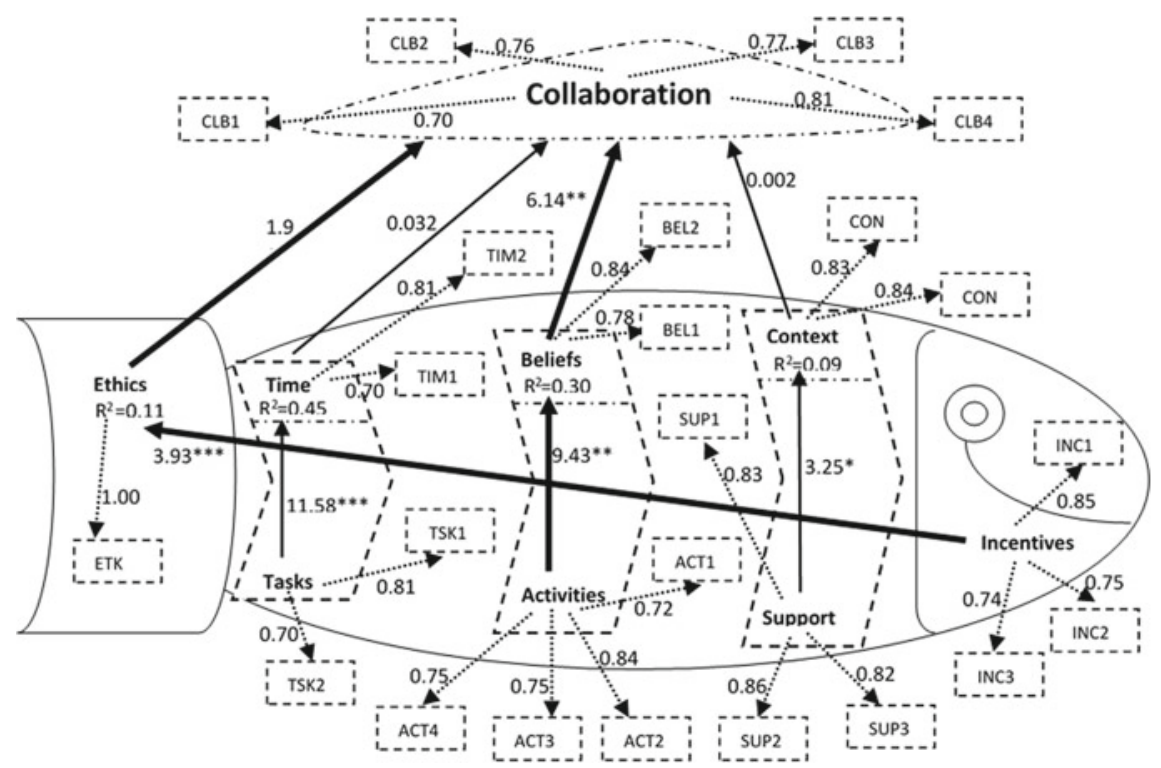

Fig. 2 Structure model (PLS bootstrapping "path coefficient"). *significant at 0.05 level (1.96); **significant at .01 level (2.58); ***significant at 0.001 level (3.29)

$p<0.001$ level) along with the relationship (H4-1) between "Ethics" and shaping "Collaboration" $(\beta=0.06, p<0.05)$.

The other two paths of predicting research collaboration are not significant. First, "Technology and support" has a significant relationship with "Context" (H3-0 at $\beta$ $=0.64, p<0.05)$, but, as a second path, the "Context" cannot predict research "Collaboration" (H3-1 at $\beta=0.00$ not significant). Second, academic "Task" connected strongly with the factor "Time" (H1-0 $\beta=-0.70, p<0.001)$. On the other hand, the relationship between "Time" and shaping academic "Collaboration" (H1-1 $\beta=-$ 0.00 , not significant) was unrelated in the context of shaping academic collaboration (Table 3).

\section{Discussion: Conclusion and Limitations}

\subsection{Conclusions}

The results of this study demonstrate the factors that might influence research collaboration among novice researchers in Germany. The study conceptualised and validated the fish model for understanding research collaboration in the digital age, highlighting where the model can be extended. A brief review of the findings raises the question of what drives researchers' propensity to collaborate using web 2.0 services. 
Table 3 Research hypotheses and conclusions

\begin{tabular}{|c|c|c|c|c|}
\hline Hypothesis & $\beta$ (path-coefficient) & $t$-value & $p$-value & Validation \\
\hline $\begin{array}{l}\text { H1-0: An academic task to be done via web } \\
2.0 \text { is driven by a timeframe (when the task } \\
\text { should be done/how much time is needed } \\
\text { to do it) }\end{array}$ & 0.70 & 12.61 & $<0.001$ & Supported \\
\hline $\begin{array}{l}\text { H1-1: An appropriate time frame for a task } \\
\text { to be carried out via web } 2.0 \text { can lead to } \\
\text { academic collaboration }\end{array}$ & -0.00 & 0.03 & n.s. & Rejected \\
\hline $\begin{array}{l}\text { H1: Novice researchers are more likely to } \\
\text { collaborate and work with each other when } \\
\text { the work task (types, stages, and } \\
\text { technologies) and time frame are specified }\end{array}$ & & & & Rejected \\
\hline $\begin{array}{l}\text { H2-0: Academic and research activities } \\
\text { (online) affect a researcher's belief in using } \\
\text { web } 2.0 \text { for collaboration }\end{array}$ & 0.67 & 9.71 & $<0.001$ & Supported \\
\hline $\begin{array}{l}\text { H2-1: Researchers' belief in using web } 2.0 \\
\text { to support research may increase their } \\
\text { chances of collaboration }\end{array}$ & 0.41 & 5.77 & $<0.001$ & Supported \\
\hline $\begin{array}{l}\text { H2: Novice researchers are more likely to } \\
\text { collaborate and work with each other when } \\
\text { they believe in the work and participate in } \\
\text { academic and research activities (online) }\end{array}$ & & & & Supported \\
\hline $\begin{array}{l}\text { H3-0: web } 2.0 \text { technology may enhance } \\
\text { research communication, leading to } \\
\text { collaboration }\end{array}$ & 0.64 & 3.74 & $<0.05$ & Supported \\
\hline $\begin{array}{l}\text { H3-1: Research context has a direct } \\
\text { influence on collaboration. }\end{array}$ & 0.00 & 0.00 & n.s. & Rejected \\
\hline $\begin{array}{l}\text { H3: Researchers are more likely to } \\
\text { collaborate when they have received } \\
\text { technical support in their academic context }\end{array}$ & & & & Rejected \\
\hline $\begin{array}{l}\text { H4-0: Incentives as an external motivation } \\
\text { can influence ethics as an internal } \\
\text { motivation for enhancing research } \\
\text { collaboration }\end{array}$ & 00.71 & 3.79 & $<0.001$ & Supported \\
\hline $\begin{array}{l}\text { H4-1: Research ethics as an internal } \\
\text { motivation is closely related to research } \\
\text { collaboration }\end{array}$ & 0.06 & 1.74 & $<0.05$ & Supported \\
\hline $\begin{array}{l}\text { H4: Novice researchers are more likely to } \\
\text { collaborate and work with each other when } \\
\text { they receive incentives (as external } \\
\text { motivation) that are protected and } \\
\text { combined with their trust and the value of } \\
\text { their work (as internal motivation) }\end{array}$ & & & & Supported \\
\hline
\end{tabular}


The first collaboration path showed that doing online doctoral research activities might shape beliefs in using web 2.0 technologies for academic purposes and, thus, enhance collaboration. An example is that using social media to connect with likeminded people eventually shapes one's belief about the importance of web 2.0. Researchers who believe in using such media are more likely to collaborate and more open to empathy.

Overall this study illustrates how the fish model can be applied to an online setting in order to understand how the interaction between academic activities and researchers' beliefs can influence research collaboration. The results are consistent with the previous mentioned literature as it was discussed by Terrell et al. (2009), being successful can shape a person's individual beliefs. Engaging in online research activities in order to communicate and collaborate reflects individual beliefs that control the actions that can enhance further collaboration offline, as has been observed in a professional context (Köhler 1997). Researchers' activities may reveal some of the individual beliefs that back and catalyse collaboration. When researchers engaged in online research activities, their belief in the use of web 2.0 in research increased. Use of web 2.0 services such as social media can also predict productive and conductive research collaboration (Pscheida et al. 2013).

The second collaboration path shows that in keeping a balance between internal "ethics" and external "incentives", motivation can confirm collaboration. An example is that researchers' trust in sharing their ideas via web 2.0 services only grows when they benefit from using such technology and, accordingly, it may lead to collaboration. These findings have important implications for the fish model. Internal and external motivations support future research collaboration. We argue that external and internal motivations are closely related; consequently, in academia both types of motivation help researchers become engaged in collaboration. Higher incentives predict higher levels of trust; researchers are more likely to collaborate when they trust the technologies they use. What motivates researchers to enhance collaboration into the web 2.0 sphere depends on the technologies they can trust and use to extend their professional networks. For collaboration among researchers, trust is synonymous with benefit, which is the catalyst for collaboration.

\subsection{Limitations}

In this study, research collaboration was defined as the use of web 2.0 technologies for communication and daily research routines (reading, searching, writing, etc.). The authors addressed a subset of the concept labelled e-science or science 2.0. They empirically observed doctoral scholars. These $\mathrm{PhD}$ students came mainly from the Faculty of Mathematics and School of Science at the Technische Universität Dresden in Germany. These aspects may limit the range and meaning of the findings presented. 
Another limiting aspect is that the fish model reported only two significant paths that may predict research collaboration. It would, however, be more informative if measures of the other paths of the fish model (that appeared as non-significant in our study) were measured once again in a different research context with another sample.

\section{Appendix}

See Tables 4, 5, and 6. 


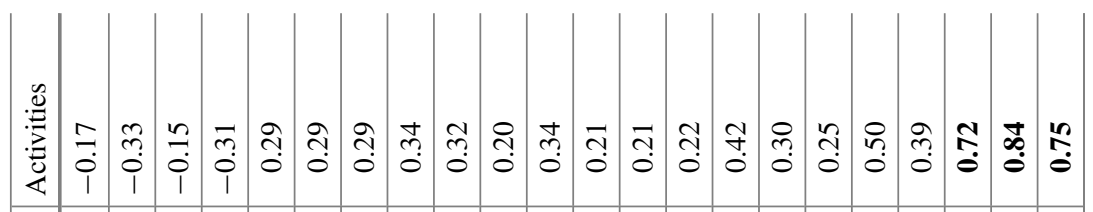

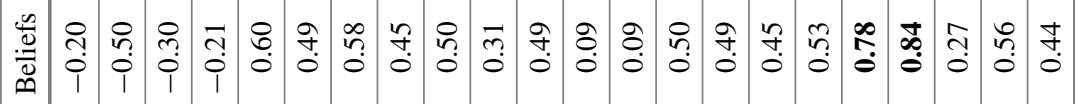

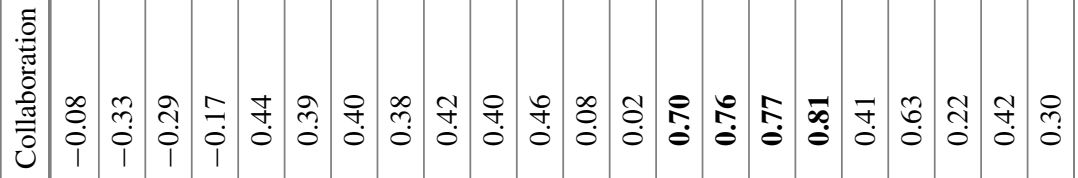

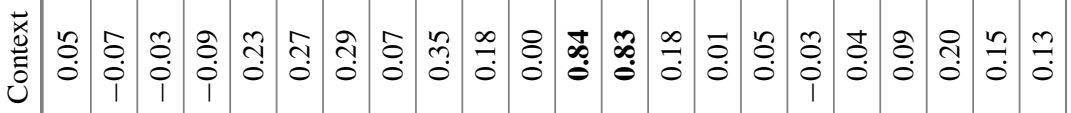

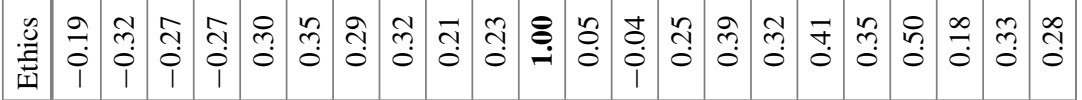

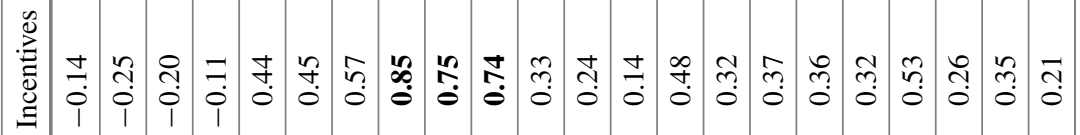
章

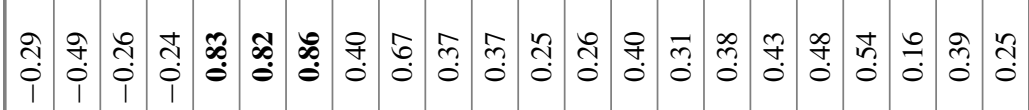

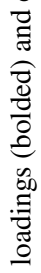

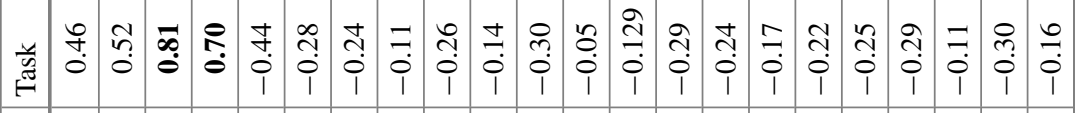

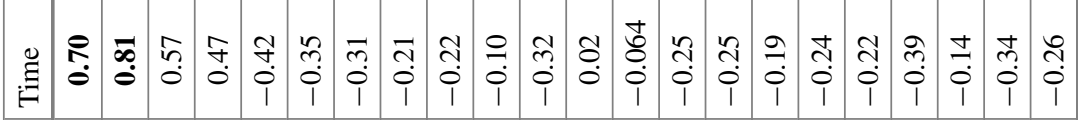

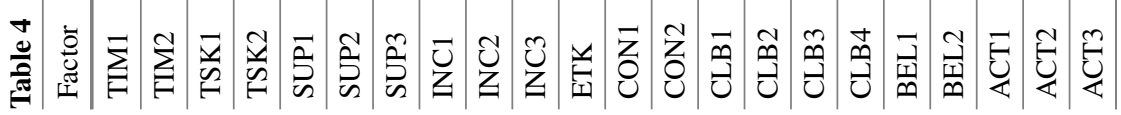




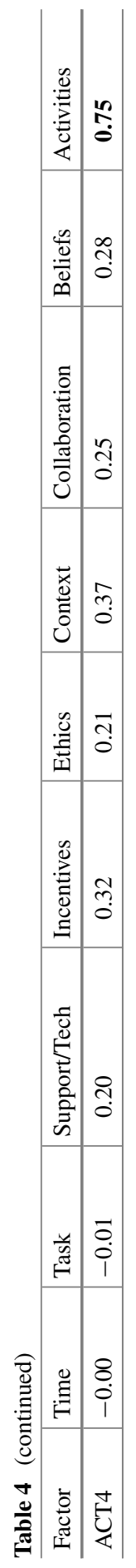


Table 5 Items removed

\begin{tabular}{|c|c|}
\hline Factor & Item \\
\hline TSK3 & $\begin{array}{l}\text { It is more effective to ask colleagues for a declaration about unclear work tasks by } \\
\text { E-Mail or Skype than face-to-face }\end{array}$ \\
\hline TSK4 & The task of reading an online paper is more effective than a printed one \\
\hline TSK5 & $\begin{array}{l}\text { Task of searching/sorting for literature review by using web } 2.0 \text { services more difficult } \\
\text { than my traditional way }\end{array}$ \\
\hline TSK5 & $\begin{array}{l}\text { When I need to effectively discuss something related to my research with colleagues, } \\
\text { web } 2.0 \text { services are not the right solution }\end{array}$ \\
\hline TIM3 & $\begin{array}{l}\text { It is necessary to invest a lot of time for communicating, researching, and working via } \\
\text { web } 2.0 \text { services }\end{array}$ \\
\hline TIM4 & $\begin{array}{l}\text { Web } 2.0 \text { services save time for organising and managing our teamwork and working in } \\
\text { a scientific community }\end{array}$ \\
\hline TIM5 & $\begin{array}{l}\text { Usage of synchronous web } 2.0 \text { services (in real time interaction) such as chat or video } \\
\text { conferences is more useful for managing online discussions than asynchronous tools } \\
\text { (e.g. online forum) }\end{array}$ \\
\hline SUP4 & $\begin{array}{l}\text { The usage of web } 2.0 \text { services in a scientific research is difficult and I can't understand } \\
\text { it }\end{array}$ \\
\hline SUP5 & I use web 2.0 services when others recommend something really interesting for me \\
\hline SUP6 & Peers and colleagues warn me to use web 2.0 services in research \\
\hline CON3 & $\begin{array}{l}\text { My institute/faculty does not formally support using web } 2.0 \text { services among doctoral } \\
\text { students }\end{array}$ \\
\hline CON4 & The best way to contact my supervisor is through e-mail \\
\hline CON5 & $\begin{array}{l}\text { Collaboratively reading, writing, and reviewing a paper via web } 2.0 \text { services in our } \\
\text { project/research group is not familiar yet }\end{array}$ \\
\hline INC4 & $\begin{array}{l}\text { Receiving daily information about a recent paper, event, or colleagues' activity, is a big } \\
\text { motivation for me to use web } 2.0 \text { services }\end{array}$ \\
\hline INC5 & $\begin{array}{l}\text { Editing, commenting, reading, and reviewing dissertation tasks by using desktop word } \\
\text { processing software are more familiar to me than using web } 2.0 \text { services }\end{array}$ \\
\hline ETK2 & $\begin{array}{l}\text { Taking on more responsibility in scientific editing, reviewing, commenting via web } 2.0 \\
\text { services among researchers is ambiguous and uncertain }\end{array}$ \\
\hline ETK3 & Web 2.0 services signify for me a place where there is a lower level of data security \\
\hline ETK4 & $\begin{array}{l}\text { Data security for me is an important issue for participating in any scientific editing, } \\
\text { reviewing, commenting, and reading via web } 2.0 \text { services }\end{array}$ \\
\hline ETK5 & My data can be stolen easily via web 2.0 services \\
\hline ACT5 & Giving online lectures is one of my usual online activities \\
\hline BLF3 & I believe that putting my data through cloud services is safe and enhances mobility \\
\hline BLF4 & Web 2.0 services may slow down my work load and research progress \\
\hline BLF5 & $\begin{array}{l}\text { Managing time, procedures, reading, writing, reviewing, and daily events are } \\
\text { effectively done without using web } 2.0 \text { services }\end{array}$ \\
\hline CLB5 & $\begin{array}{l}\text { I intend to communicate only through e-mail in scientific research, due to the fact that } \\
\text { research is an individual contribution }\end{array}$ \\
\hline
\end{tabular}


Table 6 Final measured items (items used)

\begin{tabular}{|c|c|}
\hline Factor & Item \\
\hline TSK1 & Web 2.0 services may hinder my tasks in everyday research activities \\
\hline TSK2 & $\begin{array}{l}\text { When I need to effectively discuss something related to my research with colleagues, } \\
\text { web } 2.0 \text { services are not the right solution }\end{array}$ \\
\hline TIM1 & $\begin{array}{l}\text { Web } 2.0 \text { services are not helpful services in situations when information is needed on } \\
\text { the same day }\end{array}$ \\
\hline TIM2 & $\begin{array}{l}\text { It is a waste of time to use web } 2.0 \text { services to establish communication or } \\
\text { collaboration with other colleagues in the context of doing research }\end{array}$ \\
\hline SUP1 & The uses of web 2.0 services are useful for my research \\
\hline SUP2 & $\begin{array}{l}\text { I enjoy using web } 2.0 \text { services in editing, commenting on, and reading a piece of } \\
\text { research }\end{array}$ \\
\hline $\mathrm{S} 3$ & Using web 2.0 services may help a lot to inform me about important scientific events \\
\hline CON1 & $\begin{array}{l}\text { My institute provides a proper knowledge management system/web } 2.0 \text { services (e.g. } \\
\text { website) for improving communication and collaboration among doctoral students }\end{array}$ \\
\hline CON2 & $\begin{array}{l}\text { Officially, Wiki is used as a platform for group activities and collaborative work } \\
\text { reports in my research group }\end{array}$ \\
\hline INC1 & Creating a personal profile in web 2.0 services would enhance my reputation \\
\hline INC2 & Using web 2.0 services in research helps me to satisfy my interests in my scientific area \\
\hline INC3 & Web 2.0 services facilitate the presentation of myself and marketing my research \\
\hline ETK1 & I trust sharing my data through web 2.0 services \\
\hline ACT1 & I usually engage in one or more online scientific discussions \\
\hline ACT2 & $\begin{array}{l}\text { Sharing files, links, videos, or photos with colleagues is one of my daily uses of web } \\
2.0 \text { services }\end{array}$ \\
\hline ACT3 & Peer review of scientific work via web 2.0 services is one of my usual online activities \\
\hline ACT4 & $\begin{array}{l}\text { Commenting and writing in one or more scientific online forums, weblogs, or wikis is } \\
\text { also one of my daily/weekly activities }\end{array}$ \\
\hline BLF1 & I believe that using web 2.0 services has become one of my everyday research routines \\
\hline BLF2 & I would say, to enhance academic collaboration, you should use web 2.0 services \\
\hline CL1 & $\begin{array}{l}\text { I intend to engage and involve myself in a community of practice by using web } 2.0 \\
\text { services }\end{array}$ \\
\hline CLB2 & $\begin{array}{l}\text { I intend to share my reading, writing, review, and resources with other colleagues } \\
\text { when it is mediated by web } 2.0 \text { services }\end{array}$ \\
\hline CLB3 & $\begin{array}{l}\text { I intend to coordinate and work together more when this coordination is facilitated by } \\
\text { web } 2.0 \text { services }\end{array}$ \\
\hline CLB4 & $\begin{array}{l}\text { Willingness to communicate and collaborate in research with other disciplines could } \\
\text { be enlarged by using web } 2.0 \text { services }\end{array}$ \\
\hline
\end{tabular}




\section{References}

Birnholtz, J.P.: When do researchers collaborate? Toward a model of collaboration propensity in science and engineering research. Dissertation submitted at the University of Michigan (2005)

DeAndrea, D.C.: Participatory social media and the evaluation of online behavior. Human Commun. Res. 38(04), 510-528 (2012)

Eyman, D., Sheffied, S., DeVoss, D.N.: Developing sustainable research networks in graduate education. Comput. Compos. 26, 19-57 (2009)

Forschung \& Lehre: Promotion in Deutschland: Daten und Fakten, Forschung \& Lehre, vol. 8 p. 631. http://www.forschung-und-lehre.de/wordpress/Archiv/2012/ful_08-2012.pdf (2012). Accessed 14 Apr 2015

Frewox: Large moray eel and grouper hunting together in the Red Sea. http://www.youtube.com/ watch?v=ukiw4wYwqPg (2010). Accessed 27 Oct 2012

Gillet, D., Helou, S., Joubert, M., Sutherland, R.: Science 2.0: supporting a doctoral community of practice in technology enhanced learning using social software. Science 2.0 for TEL Workshop (2009)

Illeris, K.: Learning in working life. Roskilde University Press, Frederiksberg (2004)

Jirotka, M., Procter, R., Rodden, T., Bowker, G.C.: Special issue: collaboration in e-research. Comput. Support. Coop. Work 15, 251-255 (2006)

Kahnwald, N., Albrecht, S., Herbst, S., Köhler, T.: Informelles Lernen Studierender mit Social Software unterstützen. Strategische Empfehlungen für Hochschulen; Reihe: Medien in der Wissenschaft. Waxmann, Münster (2015)

Köhler, T.: Sozialpsychologie der Kommunikation im Internet. Erkenntnisstand und Forschungsbedarf; Gardez! Verlag. [CD-ROM], Mainz (1997)

Lahenius, K.: Communities of practice supporting doctoral studies. Int. J. Manag. Educ. 10, 29-38 (2010)

Lam, A.: What motivates academic scientists to engage in research commercialization: 'Gold', 'ribbon' or 'puzzle'? Res. Policy 40(10), 1354-1368 (2011)

Lattemann, C., Köhler, T.: Trust or control-governance concepts for virtual organizations. In: Frontiers of e-Business Research, vol. 3 (2005)

Meyer, A.M., McNeal, L.: Academics online: their interests and foibles. Internet High. Educ. 14, $113-120(2011)$

Mohamed, B.: Definition of a system for the management of project-based E-learning; Doctoral Dissertation, Technische Universität, Dresden (2011)

Mohamed, B., Köhler, T., Mabed, M.: Designing e-research: A framework for researcher's social online knowledge; In: Köhler, T., Kahnwald, N.: Online Communities: Enterprise Networks, Open Education and Global Communication. Proceedings of the GeNeMe 2013. TUDPress, Dresden (2013)

Mohamed, B., Pscheida, D., Köhler, T.: The Fish Model: a conceptual framework for enhancing e-research collaboration. In: Marti, D., Gómez, L., López, A. (eds.) EDULEARN13 Proceedings. 5th International Conference on Education and New Learning Technologies. IATED. Barcelona (2013)

Mutula, S.M.: Ethics and trust in digital scholarship. Electron. Libr. 29(2), 261-276 (2010)

Patel, H., Pettitt, M., Wilson, J.R.: Factors of collaborative working: a framework for a collaboration model. Applied Ergonomica 43, 1-26 (2011)

Peggy, L.M., Borkowski, N.A.: The assessment of doctoral education: emerging criteria and new models for improving outcomes, library and information science research 29 (2007)

Pidd, H.: German defence minister resigns in PhD plagiarism row. The Guardian. http://www.gua rdian.co.uk/world/2011/mar/01/german-defence-minister-resigns-plagiarism (2011). Accessed 1 Mar 2011

Pscheida, D., Albrecht, S., Herbst, S., Minet, C., Köhler, T.: Nutzung von Social Media und onlinebasierten Anwendungen in der Wissenschaft. Erste Ergebnisse des Science 2.0-Survey 2013 des Leibniz-Forschungsverbunds "Science 2.0". TUD Press, Dresden (2014) 
Pscheida, D., Köhler, T., Mohamed, B.: What's your favorite online research tool? Use of and attitude towards Web 2.0 applications among scientists in different academic disciplines. In: Marsden, C., Tassiulas, L. (eds.) Proceedings of the 1st International Conference on Internet Science. Sigma Orionis, Brussels (2013)

Reebs, S.-G.: Cooperation in Fishes. Moncton, Canada. http://www.howfishbehave.ca/pdf/cooper ation.pdf (2011). Accessed 26 Oct 2012

Ringle, C.M., Wende, S, Will, A.: SmartPLS. Release 2.0 (beta). University of Hamburg, Hamburg (2005)

Saxony State, Statistical Branch: Abschlussprüfungen an den Hochschulen im Freistaat Sachsen. http://www.statistik.sachsen.de/download/100_Berichte-B/B_III_3_j09.pdf (2009). Accessed 24 Oct 2012

Serenko, A.: A model of user adoption of interface agents for email notification. Interact. Comput. 20, 461-472 (2008)

Tannen, D.: The Argument Culture. http://www.petracaci.com/argpp1.pdf (2006). Accessed 24 June 2012

Terrell, S.R., Snyder, M.M., Dringus, L.P.: The development, validation, and application of the doctoral student connectedness scale. Internet High. Educ. 12, 112-116 (2009)

Veletsianos, G., Kimmons, R.: Scholars and faculty members' lived experiences in online social networks. Internet Hig. Educ. 16, 43-50 (2012)

Wang, M.-L.: Scholarly journal use and reading behavior of social scientists in Taiwan. Int. Inf. Libr. Rev. 42, 269-281 (2010)

Wolters, M., Schmiedel, S.: Promovierende in Deutschland 2010. Statistisches Bundesamt, Wiesbaden retrieved from: https://www.destatis.de/DE/Publikationen/Themat isch/BildungForschungKultur/Hochschulen/Promovierende5213104109004.html (2012). Accessed 14 Apr 2015

Ynalvez, M.A., Shrum, W.M.: W.M. Professional networks, scientific collaboration, and publication productivity in resource-constrained research institutions in a developing country. Res. Policy $\mathbf{4 0 ,}$ 204-216 (2011)

Zaman, M.: Doctoral programs in the age of research2.0; In: Anandarajan, M.: e-Research Collaboration: Theory, Techniques and challenges. Springer-Verlag GmbH \& Co., Berlin and Heidelberg (2010)

Open Access This chapter is licensed under the terms of the Creative Commons Attribution 4.0 International License (http://creativecommons.org/licenses/by/4.0/), which permits use, sharing, adaptation, distribution and reproduction in any medium or format, as long as you give appropriate credit to the original author(s) and the source, provide a link to the Creative Commons license and indicate if changes were made.

The images or other third party material in this chapter are included in the chapter's Creative Commons license, unless indicated otherwise in a credit line to the material. If material is not included in the chapter's Creative Commons license and your intended use is not permitted by statutory regulation or exceeds the permitted use, you will need to obtain permission directly from the copyright holder. 